\title{
Prevalence of obstructive lung disease in an African country using definitions from different international guidelines: a community based cross-sectional survey
}

Eric Walter Pefura-Yone ${ }^{1,2^{*}}$, André Pascal Kengne ${ }^{3}$, Adamou Dodo Balkissou², Christiane Gaelle Magne-Fotso ${ }^{4}$, Martine Ngo-Yonga ${ }^{4}$, Julie Raïcha Boulleys-Nana ${ }^{4}$, Nelly Rachel Efe-de-Melingui ${ }^{4}$,

Patricia Ingrid Ndjeutcheu-Moualeu ${ }^{4}$, Charles Lebon Mbele-Onana ${ }^{4}$, Elvira Christelle Kenmegne-Noumsi ${ }^{4}$, Barbara Linda Kolontchang-Yomi ${ }^{4}$, Boris Judicaël Theubo-Kamgang ${ }^{4}$, Emilienne Régine Ebouki ${ }^{4}$,

Chrystelle Karen Djuikam-Kamga ${ }^{4}$, Francine Amougou ${ }^{4}$, Liliane Mboumtou ${ }^{4}$, Elsie Linda Petchou-Talla ${ }^{4}$,

Christopher Kuaban ${ }^{1,5}$ and Respiratory Health Survey Group in Cameroon (RHSGC)

\begin{abstract}
Background: Obstructive lung disease (OLD), a major global public health problem, has been less investigated in African countries. We assessed the prevalence and determinants of OLD in Yaounde (the capital city of Cameroon), using internationally agreed definitions.
\end{abstract}

Methods: Participants were adults (age $\geq 19$ years) screened during a community-based survey between December 2013 and April 2014. Air flow limitation (AFL) was based on a pre-bronchodilator forced expiratory volume in $1 \mathrm{~s}$ (FEV1) and forced vital capacity (FVC) below the lower limit of normal (LLN, AFL-LLN). Chronic obstructive pulmonary disease (COPD) was based on post-bronchodilator FEV1/FVC ratio < LLN (COPD-LLN).

Results: Of the 1287 subjects included, $51.9 \%$ were female, $9.3 \%$ were current smokers and their mean age was $34.4 \pm 12.8$ years. Forty-nine (3.8\%, $95 \%$ Cl 2.8-4.9\%) participants had AFL-LLN. Thirty-one subjects had COPD-LLN; giving a prevalence of COPD-LLN of (2.4\%, $95 \%$ Cl 1.6-3.3 \%). In multivariable analysis, male gender (AOR 2.42; $95 \%$ Cl 1.12-5.20) and lifetime wheezing (AOR 2.88; $95 \% \mathrm{Cl} 1.06-7.81$ ) were the determinants of COPD-LLN. Otherwise, male sex (AOR 1.93, $95 \%$ Cl 1.00-3.73), age 40-59 years (AOR 1.99, $95 \%$ Cl 1.04-3.81) and lifetime wheezing (AOR 2.65, $95 \% \mathrm{Cl} 1.13-6.20)$ remained as independent determinants of AFL-LLN.

Conclusions: Obstructive lung disease based on more accurate definitions was relatively infrequent in this population. It is important to sensitize the medical staff and the general public about this condition which should be actively investigated in individuals aged 40 years and above.

Keywords: COPD, Air flow limitation, Associated factors, Africa

\footnotetext{
*Correspondence: pefura2002@yahoo.fr

${ }^{2}$ Pneumology service, Yaounde Jamot Hospital, P.O Box: 4021, Yaounde,

Cameroon

Full list of author information is available at the end of the article
} 


\section{Background}

Chronic obstructive pulmonary disease (COPD) is a major global public health problem. The World Health Organization (WHO) has estimated that about 65 million people suffer from moderate to severe COPD worldwide [1]. A striking issue with COPD is that the condition is often underestimated by the patient, and largely under diagnosed and as a consequence undertreated by medical doctors [2]. The prevalence of COPD varies across regions and can be as high as $10 \%$ or beyond in regions with high prevalence of smoking [3]. COPD is currently the fourth leading cause of death globally, and is set according to WHO estimates to become the third leading cause of death and the fifth provider of disability worldwide by 2030 [1].

Smoking is the leading risk factor for COPD worldwide with the attributable risk fraction of COPD from active smoking ranging from 40 to $70 \%$ across countries [4-6]. With an estimated prevalence of smoking ranging from 8 to $43 \%$ in men and 5 to $30 \%$ in women, and the expanding tobacco industry across the continent, COPD is set to become a major health challenge in African countries, alongside other communicable and non-communicable diseases [7]. Although smoking is a major risk factor for COPD, it remains that a large number of those with COPD have no history of smoking habits $[8,9]$. Other contributing factors to the global burden of COPD include age greater than 40 years, air pollution, exposure to biomass, exposure to certain gases, low socioeconomic status, genetic factors, history of pulmonary tuberculosis and HIV infection $[4,8]$.

Published studies on COPD largely originate from developed countries. Very few epidemiological studies have been conducted on COPD in sub-Saharan Africa, although COPD represents the fourth cause of death in low and middle income countries [10]. Indeed, according to WHO's estimates COPD accounted for 116,000 deaths in Africa in 2001, a contribution similar to that observed in Europe [11]. In a recent systematic review, Finney et al. [6] found only nine cross-sectional studies of acceptable methodological quality on COPD in the general population in Africa. Efforts to close this knowledge gap will have to overcome the challenge of varying definitions of air flow obstruction and COPD across recommendations. For instance, American Thoracic Society/European Respiratory Society (ATS/ERS) recommends that the forced expiratory volume in $1 \mathrm{~s} /$ forced vital capacity (FEV1/ FVC) ratio < lower limit of normal (LLN) should be used to define COPD, while the global initiative for obstructive lung disease (GOLD) rather recommends that the fixed ratio of FEV1/FCV $(<0.70)$ should be used $[12,13]$. In all instances, demonstrating a chronic airflow obstruction not fully reversible after bronchodilator inhalation is essential to define COPD [3]. It is against this background that the current study was undertaken with a dual objective of: 1) determining the prevalence of obstructive lung disease (OLD) including air flow limitation (AFL) and COPD in a major city in the Central Africa Region according to the different internationally recommended definitions; and 2) investigating the determinants of these conditions among adults in this setting.

\section{Methods}

\section{Type of study, study setting and population}

This was a community-based cross-sectional survey conducted between December 2013 and April 2014 (5 months duration) across all the seven districts of Yaounde, the Capital City of Cameroon with about 2 million inhabitants including 1.4 million adults [14]. Consenting adults aged 19 years and above were considered for inclusion in the study [15]. They had to be free of any of the following conditions: pneumonia in the last 4 weeks, active thoracic tuberculosis, physical or mental impairment affecting the ability to perform spirometry. The study was approved by the institutional ethic review committee of the Faculty of Medicine and Pharmaceutical Sciences of the Douala University and the administrative authorities of the Health Delegation for the Centre Region.

\section{Sampling}

A three level stratified cluster sampling was applied. At the first level, 16 enumeration areas (EA, 2-3 per district) were selected using a simple random sampling. EA demarcations were those used in the third general population census conducted in Cameroon in 2005 [14]. Each EA comprised about 140-220 households. At the second level, one in two household was selected using a systematic sampling. The first selected household and the itinerary were those used during the national vaccination campaigns. At the third level, all individuals aged 19 years and above in selected households formed the primary statistical unit for data collection.

\section{Data collection}

Data were collected by final year undergraduate medical students who were specifically trained for this purpose. The survey involved fourteen undergraduate final year medical students and six spirometry technicians. Data collection during face-to-face interviews used a pretested questionnaire, derived from questionnaires used in international surveys [16, 17]. Data were collected on: 1) socio-demographic characteristics including age, sex, level of formal education (none, primary, secondary, university), 2) smoking history with participants distinguished as non-smokers (including never-smokers 
and lifetime smoking below 20 packs in their lifetime), smokers (including those currently smoking and with a lifetime cigarette smoking higher than 20 packs in their lifetime), and former-smokers (including those who had stopped smoking for over 6 months) [16]; 3) past history of respiratory diseases including tuberculosis, asthma, chronic bronchitis; 4) chronic respiratory symptoms including chronic cough and expectoration (lasting for at least 3 months per year), dyspnea which was graded in four stages (stage 1-shortness of breath while climbing at normal pace on mild inclined surface or a floor of the building, stage 2-shortness of breath while walking at normal pace with age mates on a flat surface, stage 3-shortness of breath while walking at own's pace on a flat surface, stage 4-shortness of breath at rest or any small effort); 5) exposure to biomass based on the exposure to cooking smoke from solid fuel, and was considered as exposed all participants living for at least 6 months in a household where solid fuel was used for cooking purposes; 6) anthropometric measurements including height (meter) measured to the nearest centimeter using a stadiometer, weight $(\mathrm{kg})$ measured with a CAMRY scale (CAMRY, Guangzhou, China), and body mass index calculated as weight $(\mathrm{kg}) /[$ height $(\mathrm{m})$ *height $(\mathrm{m})$ ].

\section{Spirometric measures}

Spirometric data were obtained for all eligible participants as per standard methods [18], using turbine pneumotachograph (Spiro USB,Care fusion, Yorba Linda-USA) or a Fleisch pneumotachograph (Spirolyser SPL-10 USB, FIM-Medical, Lyon-France), meeting the ATS 1994 standards. All measurements were performed after at least 15 min rest, with the participant in a seated position, with the back straight, and the nose clipped to allow air flow only by mouth. The ATS/ERS acceptability and reproducibility criteria were applied [19]. At least three tests were done by each participant to establish the FVC curve. Spirometric variables measured included: FEV1, FVC and the FEV1/FVC ratio. FEV1 and FVC values retained were the best out of the three tests which fulfilled the acceptability criteria (maximal difference below $5 \%$ or $150 \mathrm{ml}$ ). All participants with a FEV1/FCV below the LLN or 0.70 received $400 \mu \mathrm{g}$ of inhaled salbutamol and had the tests repeated 15 min later to assess the reversibility of AFL. Predicted values were estimated using the reference spirometric values for an African population derived by Musafiri et al. [20]. Quality control was done by regularly supervising investigators and technicians who performed spirometry. Spirometry curves were reviewed weekly by one of chest physician involved in the study (EWPY and ADB) and feedback was made to technicians.
All spirometric tests results were reviewed by an experienced chest physician (EWPY or ADB).

\section{Operational definitions}

Operational definitions were those recommended by the ATS/ERS (the use of LLN of FEV1/FVC ratio) [13] or by the global initiative for chronic obstructive lung disease (GOLD) [fixed cut-off of 0.70 for the FEV1/FVC ratio] [21]. Air flow limitation (AFL) was defined by a prebronchodilator FEV1/FVC < LLN (AFL-LLN) or below 0.70 (AFL-fixed cut-off). COPD was defined by a postbronchodilator FEV1/FVC below the LLN (COPD-LLN) or below 0.70 (COPD-fixed cut-off). The severity of AFL or COPD was based on the modified 2006 GOLD stages [13]: stage I (mild) -FEV1 $\geq 80 \%$ of the predicted value; Stage II (moderate)-FEV1 comprised between 50-80 \% of the predicted value; Stage III and IV (severe)FEV $1<50 \%$ of the predicted value.

\section{Statistical methods}

The sample size was calculated by estimating the population of adults aged 19 years and above to be 1.4 million. For a type I error of $5 \%$, an estimated prevalence of $4.5 \%$ for COPD [22], and a precision of $1.5 \%$, the required sample size was 733 individuals. Considering a correction factor of 1.5 for the cluster effect, and a nonresponse rate of $10 \%$, the final estimated sample size was 1210 individuals. Data analysis used the IBM-SPSS v.20 for Windows (IBM, Chicago, USA). Categorical variables were presented as count and frequencies, and continuous variables as mean and standard deviation (SD) or median and 25th-75th percentiles. Group comparisons used Chi square test and Fisher exact test for qualitative variables, and Student's t test and equivalents for quantitative variables. Logistic regression models were used to investigate the determinants of AFL and COPD. Significant variables in univariable analysis (based on a threshold $\mathrm{p}<0.10$ ) were entered together in the same multivariable model and the significant ones retained as the final determinants. A p value $<0.05$ was used to characterize statistically significant results.

\section{Results}

\section{Study population}

A total of 1612 participants were invited to take part in the study, of whom 57 declined, and a further 56 participants were excluded for a contraindication to spirometry or incomplete questionnaires. Of the 1499 participants who had spirometric tests done, 212 had incorrect maneuvers. Therefore 1287 were included in the final analytic sample even though, 11 participants among those with a pre-bronchodilator AFL did not have a postbronchodilator spirometric test (Fig. 1). 


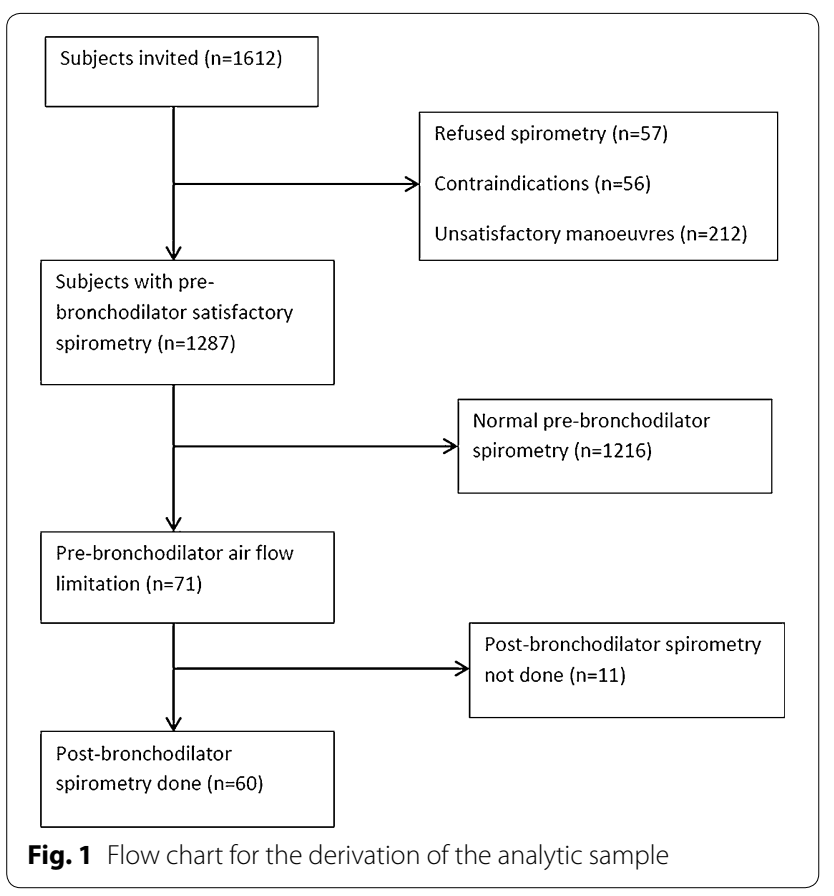

The baseline characteristics of participants are depicted in Table 1. Of the 1287 participants included, 668 (51.9\%) were women and $619(48.1 \%)$ were men. The mean age was $34.4 \pm 12.8$ years. Of the 1283 participants with known status for smoking, $9.3 \%$ were smokers and $6.8 \%$ were ex-smokers. There were more male than female smokers ( 17 vs $2.3 \%, \mathrm{p}<0.001)$. The median $(25$ th -75 th percentile) quantity of tobacco smoked was $4.3(1.2-13.7)$ pack-years. Only 28 (15.6 \%) smokers and ex-smokers had a cumulative quantity of smoked of 20 pack-years or more. Dyspnea was more frequent in women $(6.1 \%)$ than in men $(2.7 \%), p=0.003$. A history of pulmonary tuberculosis was found in 21 (1.6\%) participants. Chronic expectoration and lifetime wheezing were found in 0.8 and $6.6 \%$ of the participants, respectively.

\section{Prevalence and severity of obstructive lung disease}

The prevalence of AFL and COPD are shown in Table 1. Forty-nine ( $3.8 \%$, $95 \%$ CI 2.8-4.9\%) participants had AFL-LLN while $9(0.7 \%$, $95 \%$ CI $0.2-1.2 \%)$ had AFLfixed ratio. Thirty-three (69.4\%), $13(26.5 \%)$ and $2(4.1 \%)$ participants were respectively classified as having mild, moderate and severe AFL-LLN.

Thirty-one participants had COPD-LLN, giving a prevalence of COPD-LLN of $2.4 \%$ (95 \% CI 1.6-3.3 \%). The prevalence of COPD-fixed ratio was $0.5 \%$ (95\% CI 0.1-0.9\%). Mild, moderate and severe COPD-LLN was respectively found in $67.7,19.4$ and $12.9 \%$ of participants with COPD-LLN.

\section{Determinants of air flow limitation}

Univariable analysis of determinants of air flow limitation (AFL-LLN) is found in Tables 2. In univariable analyses, men were more affected than women (5.2 vs. $2.5 \%, \mathrm{p}=0.014)$. The prevalence of AFL-LLN was much higher in participants aged 40-59 years (5.6\%), and 60 years and above $(7.1 \%)$ than those aged $19-39$ years (3\%). Ten (20.4\%) participants with AFL-LLN were current smokers vs. 110 (8.9\%) in those without AFL-LLN $(\mathrm{p}=0.008)$. The prevalence of AFL-LLN was similar in participants exposed to biomass than in the non-exposed ( 3.7 vs. $3.9 \%, p=0.893$ ). The prevalence of AFL-LLN was higher in participants with self-reported positive status for HIV than in those with unknown HIV status. Lifetime wheezing was more frequent in participants with AFL-LLN than in those without (14.3 vs. $6.3 \%, \mathrm{p}=0.0038$ ). In multivariable analysis including all variables with a $\mathrm{p}$ value $<0.10$, male sex (AOR 1.93 , $95 \%$ CI 1.00-3.73), age 40-59 years (AOR 1.99, $95 \%$ CI 1.04-3.81) and lifetime wheezing (AOR 2.65, $95 \%$ CI 1.13-6.20) remained as independent determinants of AFL-LNN (Table 3).

Quality control was done by regularly supervising investigators and technicians who performed spirometry. Spirometry curves were reviewed weekly by one of chest physician who participated in the study (EWPY and $\mathrm{ADB})$ and feedback was made to technicians.

\section{Determinants of COPD}

Twenty-one (67.7 \%) participants with COPD-LLN and 587 (47.1\%) participants without COPD-LLN were men $(\mathrm{p}=0.023)$. The prevalence of lifetime wheezing was $16.1 \%$ among those with COPD-LLN and $6.4 \%$ among those without ( $\mathrm{p}=0.033$ ), Table 4 . No significant association was found between pulmonary tuberculosis, HIV status, BMI and COPD-LLN (Table 4). In multivariable analysis, male gender (AOR 2.42; $95 \%$ CI 1.12-5.20) and lifetime wheezing (AOR 2.88; 95 \% CI 1.06-7.81) were the determinants of COPD-LLN (Table 3).

\section{Discussion}

In this study conducted in a major city in sub-Saharan Africa using internationally accepted criteria to define AFL and COPD, the main findings were the following: 1) the prevalence of airway obstruction was 3.8 and $0.7 \%$ using respectively the LLN and fixed ratio of 0.70 for FEV1/FVC to define airway obstruction; 2) the prevalence of COPD was 2.4 and $0.5 \%$ using respectively the LLN and fixed ratio to define COPD; 3 ) determinants of AFL-LLN were male sex, age, and wheezing, while 4) male sex and wheezing were the determinants of COPD-LLN. 
Table 1 Characteristics of subjects included in the study in Yaounde, Cameroun

\begin{tabular}{|c|c|c|c|c|}
\hline Characteristics & Overall $n=1287(\%)$ & Men $\mathrm{n}=619(\%)$ & Women $n=668(\%)$ & $p$ \\
\hline \multicolumn{5}{|l|}{ Age, years } \\
\hline Mean (SD) & $34.4(12.8)$ & $34.2(13.1)$ & $34.5(12.4)$ & 0.309 \\
\hline Median (25th-75th percentiles) & $30(24-42)$ & $30(24-42)$ & $31(25-42)$ & 0.312 \\
\hline Min-Max & $19-83$ & $19-81$ & $19-83$ & / \\
\hline \multicolumn{5}{|l|}{ Age group, years } \\
\hline $19-39$ & $911(70.8)$ & $446(72.1)$ & $465(69.6)$ & \multirow[t]{3}{*}{0.124} \\
\hline $40-59$ & $306(23.8)$ & $134(21.6)$ & $172(25.7)$ & \\
\hline$\geq 60$ & $70(5.4)$ & $39(6.3)$ & $31(4.6)$ & \\
\hline \multicolumn{5}{|l|}{ Level of education } \\
\hline$\leq$ secondary & $854 / 1285(66.5)$ & $363 / 618(58.7)$ & $491 / 667(73.6)$ & \multirow[t]{2}{*}{$<0.001$} \\
\hline Higher education & $431 / 1285(33.5)$ & 255/618 (41.3) & $176 / 667(26.4)$ & \\
\hline \multicolumn{5}{|l|}{ Subject/chamber } \\
\hline$\leq 2$ & $711 / 1281(55.5)$ & $384 / 617(62.2)$ & $327 / 664(49.2)$ & \multirow[t]{2}{*}{$<0.001$} \\
\hline$>2$ & $570: 1281(44.5)$ & 233:617 (37.8) & $337 / 664(50.8)$ & \\
\hline \multicolumn{5}{|l|}{ Tobacco smoking } \\
\hline Current smoker & 120/1283 (9.4) & $105 / 618(17)$ & 15/665 (2.3) & \multirow[t]{3}{*}{$<0.00$} \\
\hline Ex-smokers & $87 / 1283(6.8)$ & $76 / 618(12.3)$ & $11 / 665(1.7)$ & \\
\hline Non smokers & 10/1283 (83.9) & $437 / 618(70.7)$ & 639/665 (96.1) & \\
\hline \multicolumn{5}{|l|}{ Cooking fuel } \\
\hline Clean & $557 / 1252(44.5)$ & $313 / 659(52.8)$ & 244/593 (37) & \multirow[t]{3}{*}{$<0.001$} \\
\hline Biomass & $99 / 1252(7.9)$ & $3 / 659(6.6)$ & 60/593 (9.1) & \\
\hline Mixed & $596 / 1252(47.6)$ & $241 / 659(40.6)$ & $355 / 593(53.9)$ & \\
\hline \multicolumn{5}{|l|}{ Past history of TB } \\
\hline No & $1266(98.4)$ & $608(98.2)$ & $658(98.5)$ & \multirow[t]{2}{*}{0.692} \\
\hline Yes & $21(1.6)$ & $11(1.8)$ & $10(1.5)$ & \\
\hline \multicolumn{5}{|l|}{ Past history of pneumonia } \\
\hline No & 1250/1286 (97.2) & $598 / 619(48.1)$ & 652/667 (97.8) & \multirow[t]{2}{*}{0.214} \\
\hline Yes & $36 / 1286(2.8)$ & $21 / 619(3.4)$ & $15 / 667(2.2)$ & \\
\hline \multicolumn{5}{|l|}{ HIV infection } \\
\hline No & $1005(78.1)$ & $456(73.7)$ & $549(82.2)$ & \multirow[t]{3}{*}{$<0.001$} \\
\hline Yes & $11(0.9)$ & $4(0.6)$ & $7(1)$ & \\
\hline Don't know & $271(21.1)$ & $159(25.7)$ & $112(16.8)$ & \\
\hline \multicolumn{5}{|l|}{ Chronic cough } \\
\hline No & $1262(98.1)$ & $607(98.1)$ & $655(98.1)$ & \multirow[t]{2}{*}{0.992} \\
\hline Yes & $25(1.9)$ & $12(1.9)$ & $13(1.9)$ & \\
\hline \multicolumn{5}{|l|}{ Chronic expectoration } \\
\hline No & $1277(99.2)$ & $614(99.2)$ & $663(99.3)$ & \multirow[t]{2}{*}{$>0.999$} \\
\hline Yes & $10(0.8)$ & $5(0.8)$ & $5(0.7)$ & \\
\hline \multicolumn{5}{|l|}{ Chronic dyspnea } \\
\hline No & $1229(95.5)$ & $602(97.3)$ & $627(93.9)$ & 0.003 \\
\hline Yes & $58(4.5)$ & $17(2.7)$ & $41(6.1)$ & \\
\hline Wheezes & & & & \\
\hline No & 1198/1283 (93.4) & $583 / 617(48.1)$ & 615/666 (92.3) & 0.122 \\
\hline Yes & $85 / 1283(6.6)$ & $34 / 617(5.5)$ & $51 / 666(7.7)$ & \\
\hline $\mathrm{BMI}, \mathrm{kg}$, mean(SD) & $26.4(5.4)$ & $25.3(4.3)$ & $27.5(6.1)$ & $<0.001$ \\
\hline AFL-pre-LLN & & & & \\
\hline Yes & $49(3.8)$ & $32(5.2)$ & $17(2.5)$ & 0.014 \\
\hline No & $1238(96.2)$ & 587 (94.8) & $651(97.5)$ & \\
\hline
\end{tabular}


Table 1 continued

\begin{tabular}{|c|c|c|c|c|}
\hline Characteristics & Overall $n=1287(\%)$ & Men n = $619(\%)$ & Women n = 668 (\%) & $\mathbf{p}$ \\
\hline \multicolumn{5}{|l|}{ AFL-fixed ratio } \\
\hline Yes & $9(0.7)$ & $6(1)$ & $3(0.4)$ & 0.263 \\
\hline No & 1278 (99.3) & $613(99)$ & $665(99.6)$ & \\
\hline \multicolumn{5}{|l|}{ COPD-LLN } \\
\hline Yes & $31 / 1276(2.4)$ & 21/608 (3.5) & 10/668 (1.5) & 0.023 \\
\hline No & $1245 / 1276(97.6)$ & $587 / 608(96.5)$ & $587 / 668(96.5)$ & \\
\hline \multicolumn{5}{|l|}{ COPD-fixed-ratio } \\
\hline Yes & $7 / 1276(0.5)$ & $4(0.7)$ & $3(0.4)$ & 0.715 \\
\hline No & 1269/1276 (99.5) & 604/608 (99.3) & 665/668 (99.6) & \\
\hline
\end{tabular}

$S D$ standard deviation, HIV human immunodefiency virus, BMI body mass index, AFL airflow limitation, LLN lower limit of normal, COPD chronic obstructive pulmonary disease

Table 2 Factors associated to air flow limitation (AFL-LLN) in univariable analysis

\begin{tabular}{|c|c|c|c|c|}
\hline Characteristics & AFL-LLN n = 49 (\%) & No AFL $n=1238(\%)$ & COR $(95 \% \mathrm{Cl})$ & p value \\
\hline \multicolumn{5}{|l|}{ Sex } \\
\hline Male & $32(65.3)$ & $587(47.4)$ & $2.09(1.15-3.80)$ & 0.014 \\
\hline Female & $17(34.7)$ & $651(52.6)$ & 1 & \\
\hline Age, years, m (SD) & $39.1(15.2)$ & $34.2(12.6)$ & $1.03(1.01-1.05)$ & 0.008 \\
\hline \multicolumn{5}{|l|}{ Age group } \\
\hline 19-39 & $27(55.1)$ & $884(71.4)$ & 1 & \\
\hline $40-60$ & $17(34.7)$ & $289(23.3)$ & $1.93(1.03-3.58)$ & 0.036 \\
\hline$\geq 60$ & $5(10.2)$ & $65(5.3)$ & $2.52(0.94-6.76)$ & 0.071 \\
\hline \multicolumn{5}{|l|}{ Level of education } \\
\hline$\leq$ Secondary & $32 / 48(66.7)$ & $822 / 1237$ (66.5) & $1.01(0.55-1.86)$ & 0.975 \\
\hline Higher education & 16/48 (33.3) & 415/1237 (33.5) & 1 & \\
\hline \multicolumn{5}{|l|}{ Subject/chamber } \\
\hline$\leq 2$ & $26(53.1)$ & $689 / 1236(55.7)$ & 1 & 0.711 \\
\hline$>2$ & $23(46.9)$ & $547 / 1236(44.3)$ & $1.11(0.63-1.98)$ & \\
\hline \multicolumn{5}{|l|}{ Tobacco smoking } \\
\hline Current smoker & $10(20.4)$ & 110/1234 (8.9) & $2.70(1.30-5.61)$ & 0.008 \\
\hline Ex-smokers & $4(8.2)$ & 83/1234 (6.7) & $1.43(0.50-4.13)$ & 0.505 \\
\hline Non smokers & $35(71.4)$ & 1041/1234 (84.4) & 1 & \\
\hline \multicolumn{5}{|l|}{ Cooking fuel } \\
\hline Biomass & $1 / 43(2.3)$ & $98 / 1209(8.1)$ & $0.32(0.04-2.46)$ & 0.276 \\
\hline Mixed & 25/43 (58.1) & $571 / 1209(47.2)$ & $1.39(0.74-2.60)$ & 0.303 \\
\hline Clean & 17/43 (39.5) & $540 / 1209(44.7)$ & 1 & \\
\hline \multicolumn{5}{|l|}{ Past history of TB } \\
\hline No & $48(98)$ & $1218(98.4)$ & 1 & \\
\hline Yes & $1(2)$ & $20(1.6)$ & $1.27(0.17-9.65)$ & 0.818 \\
\hline \multicolumn{5}{|c|}{ Past history of pneumonia } \\
\hline No & $47(95.9)$ & $1203(97.3)$ & 1 & \\
\hline Yes & $2(4.1)$ & $34(2.7)$ & $1.51(0.35-6.45)$ & 0.582 \\
\hline \multicolumn{5}{|l|}{ HIV infection } \\
\hline No & $33(67.3)$ & $972(78.5)$ & 1 & \\
\hline Yes & $1(2)$ & $10(0.8)$ & $2.95(0.37-23.69)$ & 0.310 \\
\hline Don't know & $15(30.6)$ & $256(20.7)$ & $1.73(0.92-3.23)$ & 0.087 \\
\hline \multicolumn{5}{|l|}{ Chronic cough } \\
\hline No & $48(98)$ & $1214(98.1)$ & 1 & \\
\hline Yes & $1(2)$ & $24(1.9)$ & $1.05(0.14-7.95)$ & $>0.999$ \\
\hline
\end{tabular}


Table 2 continued

\begin{tabular}{lccc}
\hline Characteristics & AFL-LLN $\mathbf{n}=\mathbf{4 9}(\%)$ & No AFL $\mathbf{n}=\mathbf{1 2 3 8}(\%)$ & COR (95 \% Cl) \\
\hline Chronic expectoration & & & 1 \\
No & $48(98)$ & $1229(99.3)$ & $2.85(0.35-22.91)$ \\
Yes & $1(2)$ & $9(0.7)$ & 1 \\
Chronic dyspnoea 1 & $48(98)$ & $1181(95.4)$ & $0.43(0.06-3.18)$ \\
No & $1(2)$ & $57(4.6)$ & 1 \\
Yes & $42(85.7)$ & $1156 / 1234(93.7)$ & 0.323 \\
Lifetime wheezing & $7(14.3)$ & $78 / 1234(6.3)$ & $2.47(1.08-5.68)$ \\
No & $25.8(4.4)$ & $26.5(5.45)$ & $0.98(0.92-1.03)$ \\
Yes & & 0.722 \\
BMl, kg, $\mathrm{m}(\mathrm{SD})$ &
\end{tabular}

$m$ mean, $S D$ standard deviation, $T B$ tuberculosis, BMI body mass index, $A F L$ air flow limitation, $L L N$ lower limit of normal

The few available studies on OLD in urban Africa using a pre-bronchodilator FEV1/FVC $<0.70$ to define airway obstruction $[23,24]$ include a study from Nigeria in 2002 and a study from South Africa in 2009 in which the prevalences of airway obstruction were 9.3 and $26 \%$ respectively. In the USA, the prevalence of bronchial obstruction based on a fixed pre-bronchodilator ratio has been reported to be about $20.9 \%$ [25]. These rates were

Table 3 Multivariable analysis of factors associated to air flow limitation and chronic obstructive lung disease

\begin{tabular}{|c|c|c|c|c|}
\hline \multirow[t]{2}{*}{ Factors } & \multicolumn{2}{|l|}{ AFL-LLN } & \multicolumn{2}{|l|}{ COPD-LLN } \\
\hline & $\begin{array}{l}\text { Adjusted OR } \\
(95 \% \mathrm{Cl})\end{array}$ & $p$ value & $\begin{array}{l}\text { Adjusted OR } \\
(95 \% \mathrm{Cl})\end{array}$ & $p$ value \\
\hline \multicolumn{5}{|l|}{ Sex } \\
\hline Female & 1 & & 1 & \\
\hline Male & $1.93(1.00-3.73)$ & 0.049 & $2.42(1.12-5.20)$ & 0.024 \\
\hline \multicolumn{5}{|l|}{ Age group, years } \\
\hline $19-39$ & 1 & & 1 & \\
\hline $40-59$ & $1.99(1.04-3.81)$ & 0.037 & $1.33(0.57-3.09)$ & 0.504 \\
\hline$\geq 60$ & $2.16(0.79-5.92)$ & 0.134 & $2.52(0.82-7.73)$ & 0.106 \\
\hline \multicolumn{5}{|l|}{ Tobacco smoking } \\
\hline Non smokers & 1 & & / & / \\
\hline Current smoker & $1.86(0.84-4.07)$ & 0.124 & / & / \\
\hline Ex-smokers & $0.81(0.26-2.52)$ & 0.713 & / & / \\
\hline \multicolumn{5}{|l|}{ HIV infection } \\
\hline No & 1 & & / & / \\
\hline Yes & $3.94(0.47-33.21)$ & 0.208 & / & / \\
\hline Don't know & $1.62(0.85-3.06)$ & 0.140 & / & / \\
\hline \multicolumn{5}{|c|}{ Lifetime wheezing } \\
\hline No & 1 & & 1 & \\
\hline Yes & $2.65(1.13-6.20)$ & 0.024 & $2.88(1.06-7.81)$ & 0.037 \\
\hline
\end{tabular}

$T B$ tuberculosis, HIV human immunodeficiency virus, $A F L$ air flow limitation, $C O P D$ chronic obstructive pulmonary disease, $L L N$ lower limit of normal, $O R$ odd's ration, $\mathrm{Cl}$ confidence interval higher than those found in our study. Globally, the prevalence of airway obstruction based on pre-bronchodilator's LLN ranges between 9 and $24 \%$ in the 40 year and above age group [24]. The rate of airway obstruction in our study based on pre-bronchodilator's LLN, both in the total population and in those aged 40 years and above, were at the lower tail of reported figures from around the world.

The prevalence of COPD based on a fixed post-bronchodilator ratio was $0.5 \%$ in our population, which is lower than the 11-25\% reported rate from other regions around the world $[22,24,26]$. Based on a more appropriate definition for our young population (i.e. post-bronchodilator LLN) to diagnose COPD, the prevalence was $2.1 \%$ in the general population and $3.2 \%$ among those aged 40 years and above $[27,28]$. This was lower than the 7-20\% reported elsewhere [24]. However, it was close to the $4.5 \%$ reported by Musafari et al. in Rwanda based on the same definition [22].

The overall low prevalence of airway obstruction in our study regardless of diagnostic criteria is at least in part explained by the low prevalence of smoking in our population. In this study, the prevalence of current and former smoking was $16.2 \%$ and only $15.6 \%$ of smokers and ex-smokers had a cumulative quantity of smoked of 20 pack-years or more. This is at variance with the very high prevalence of smoking in regions with high prevalence of COPD $[24,25]$. The low prevalence of COPD in our study could also be explained by the young age of our sample. This young age however is in keeping with the age structure of the Cameroon population [14]. COPD is more frequent in men than in women in our study in accordance with studies from developed countries [29]. This sex differential was however not found in a recent systematic review conducted by Adeloye et al., which included studies from sub-Saharan Africa [30]. Other well-known risk factors for COPD such as 
Table 4 Factors associated to chronic obstructive pulmonary disease (COPD-LLN) in univariable analysis

\begin{tabular}{|c|c|c|c|c|}
\hline Characteristics & COPD $n=31(\%)$ & No COPD $n=1245(\%)$ & OR (95 \% Cl) & $\mathrm{p}$ value \\
\hline \multicolumn{5}{|l|}{ Sex } \\
\hline Male & $21(67.7)$ & $587(47.1)$ & $2.35(1.10-5.04)$ & 0.023 \\
\hline Female & $10(32.3)$ & $658(52.9)$ & 1 & \\
\hline Age, years, m (SD) & $38.5(14.1)$ & $34.2(12.7)$ & $1.02(1.00-1.05)$ & 0.071 \\
\hline \multicolumn{5}{|l|}{ Age group } \\
\hline 19-39 & $19(61.3)$ & $887(71.2)$ & 1 & \\
\hline $40-60$ & $8(25.8)$ & $292(23.5)$ & $1.28(0.55-2.95)$ & 0.564 \\
\hline$\geq 60$ & $4(12.9)$ & $66(5.3)$ & $2.83(0.94-8.56)$ & 0.066 \\
\hline \multicolumn{5}{|l|}{ Level of education } \\
\hline$\leq$ Secondary & $21 / 30(70)$ & $825 / 1244(66.3)$ & $1.19(0.54-2.61)$ & 0.673 \\
\hline Higher education & 9/30 (30) & 419/1244 (33.7) & 1 & \\
\hline \multicolumn{5}{|l|}{ Subject/chamber } \\
\hline$\leq 2$ & $16(61.6)$ & 695/1243 (55.9) & 1 & 0.634 \\
\hline$>2$ & $15(48.4)$ & $548 / 1243(44.1)$ & $0.84(0.41-1.72)$ & \\
\hline \multicolumn{5}{|l|}{ Tobacco smoking } \\
\hline Current smoker & $4(12.9)$ & $113 / 1241(9.1)$ & $1.55(0.53-4.52)$ & 0.432 \\
\hline Ex-smokers & $3(9.7)$ & $84 / 1241(6.8)$ & $1.55(0.46-5.27)$ & 0.479 \\
\hline Non smokers & $24(77.4)$ & 1044/1241 (84.1) & 1 & \\
\hline \multicolumn{5}{|l|}{ Cooking fuel } \\
\hline Clean & 9/27 (33.3) & $544 / 1214(44.8)$ & 1 & \\
\hline Biomass & $1(3.7)$ & $97(8)$ & $0.62(0.08-4.97)$ & 0.655 \\
\hline Mixed & $17(63)$ & $573(47.2)$ & $1.79(0.79-4.06)$ & 0.161 \\
\hline \multicolumn{5}{|l|}{ Past history of TB } \\
\hline No & $30(96.8)$ & 1226/1245 (98.5) & 1 & \\
\hline Yes & $1(3.2)$ & 19/1245 (1.5) & $2.15(0.28-16.60)$ & 0.391 \\
\hline \multicolumn{5}{|c|}{ Past history of pneumonia } \\
\hline No & $30(96.8)$ & 1209/1244 (97.2) & 1 & \\
\hline Yes & $1(3.2)$ & $35 / 1244(2.8)$ & $1.15(0.15-8.68)$ & 0.891 \\
\hline \multicolumn{5}{|l|}{ HIV infection } \\
\hline No & $20(64.5)$ & $977 / 1245(78.5)$ & 1 & \\
\hline Yes & $1(3.2)$ & 10/1245 (0.8) & $4.86(0.60-40.00)$ & 0.139 \\
\hline Don't know & $10(32.3)$ & $258 / 1245(20.7)$ & $1.89(0.88-4.10)$ & 0.105 \\
\hline \multicolumn{5}{|c|}{ Chronic cough/expectoration } \\
\hline No & $30(96.8)$ & 1219/1245 (97.9) & 1 & \\
\hline Yes & $1(3.2)$ & 26/1245 (2.1) & $1.56(0.21-11.89)$ & 0.489 \\
\hline \multicolumn{5}{|l|}{ Chronic dyspnea } \\
\hline No & $30(96.8)$ & 1188/1245 (95.4) & 1 & \\
\hline Yes & $1(3.2)$ & $57 / 1245(4.6)$ & $0.70(0.09-5.19)$ & $>0.999$ \\
\hline \multicolumn{5}{|l|}{ Lifetime wheezing } \\
\hline No & $26(83.9)$ & 1161/1241 (93.6) & 1 & \\
\hline Yes & $5(16.1)$ & $80(6.4)$ & $2.79(1.04-7.46)$ & 0.033 \\
\hline $\mathrm{BMI}, \mathrm{kg}, \mathrm{m}(\mathrm{SD})$ & $27.2(4.6)$ & $26.4(5.5)$ & $1.02(0.96-1.09)$ & 0.445 \\
\hline
\end{tabular}

OR odd's ration, $M$ mean, $S D$ standard deviation, $T B$ tuberculosis, $B M I$ body mass index, COPD chronic obstructive pulmonary disease, $L L N$ lower limit of normal

pulmonary tuberculosis, HIV infection, exposure to biomass were not associated with LLN-COPD in our study, likely reflecting the low statistical power due to the low prevalence of those characteristics in the general population.
The potential limitations of this study include the small number of participants' age 40 years and above, and the inclusion of participants exclusively from urban areas. However, considering that non-tobacco related determinants of COPD can operate at any age, the inclusion in 
prevalence studies of COPD of a much broader age range is justified. Exposure to biomass is usually more important in rural than urban areas, and it is possible that including rural participants could modify some of our findings. van Gemert et al. have recently found the COPD prevalence to be $16.2 \%$ in rural Uganda region with high level of biomass utilisation [31]. Our study also has major strengths. It is the first study in Cameroon and the entire central Africa region to use spirometry to assess the population burden of COPD. It is therefore a useful addition to existing studies on this topic from Africa $[6,30]$.

\section{Conclusions}

Airway obstruction was relatively low in this central African population with low smoking habits, with substantial evidence that the prevalence increased with advanced age. It is important to sensitize the population and decision maker on this likely growing health treats. Larger studies comprising rural participants are needed to refine the findings from the current study.

\begin{abstract}
Abbreviations
AFL: air flow limitation; ATS/ERS: American Thoracic Society/European Respiratory Society; COPD: chronic obstructive pulmonary disease; EA: enumeration areas; FEV1: forced expiratory volume in $1 \mathrm{~s}$; FVC: forced vital capacity; GOLD: global initiative for chronic obstructive lung disease; LLN: lower limit of normal; OLD: obstructive lung disease.
\end{abstract}

\section{Authors' contributions}

EWPY conceived the study, supervised data collection, co-analysed the data and drafted of the manuscript; APK contributed to data analysis, drafting and critical revision of the manuscript. ADB, JRBN, REM, PINM, CLMO, ECKN, BLKY, BJTK, ERE, CKDK, CGMF, FA, LM, MNY and ELPT collected data, contributed to data analysis and critically revised the manuscript, CK contributed to the conception of study and critical revision of the manuscript; All authors read and approved the final manuscript.

\section{Author details}

${ }^{1}$ Department of Internal Medicine and Subspecialties, Faculty of Medicine and Biomedical Sciences, University of Yaounde I, Yaounde, Cameroon. ${ }^{2}$ Pneumology service, Yaounde Jamot Hospital, P.O Box: 4021, Yaounde, Cameroon. ${ }^{3}$ South African Medical Research Council \& University of Cape Town, Cape Town, South Africa. ${ }^{4}$ Institut Supérieur de Technologie Médicale, Yaounde, Cameroon. ${ }^{5}$ Faculty of Heath Sciences, University of Bamenda, Bamenda, Cameroon.

\section{Acknowledgements}

None.

\section{Competing interests}

The authors declare that they have no competing interests.

Received: 11 March 2015 Accepted: 23 November 2015

Published online: 25 February 2016

\section{References}

1. World Health Organisation: Burden of COPD (2015), http://www.who.int/ respiratory/copd/burden/en/. Accessed 22 Feb 2015.

2. van Schayck CP, Chavannes NH. Detection of asthma and chronic obstructive pulmonary disease in primary care. Eur Respir J Suppl. 2003;39:16s-22s.
3. Gupta RP, Perez-Padilla R, Marks G, Vollmer W, Menezes A, Burney P. Summarising published results from spirometric surveys of COPD: the problem of inconsistent definitions. Int J Tuberc Lung Dis. 2014;18:998-1003.

4. Johnson P, Balakrishnan K, Ramaswamy P, Ghosh S, Sadhasivam M, Abirami $\mathrm{O}$, et al. Prevalence of chronic obstructive pulmonary disease in rural women of Tamilnadu: implications for refining disease burden assessments attributable to household biomass combustion. Glob Health Action. 2011;4:7226.

5. Gingo MR, Balasubramani GK, Rice TB, Kingsley L, Kleerup EC, Detels R, et al. Pulmonary symptoms and diagnoses are associated with hiv in the MACS and WHIS cohorts. BMC Pulm. Med. 2014;14:75.

6. Finney LJ, Feary JR, Leonardi-Bee J, Gordon SB, Mortimer K. Chronic obstructive pulmonary disease in sub-Saharan Africa: a systematic review. Int J Tuberc Lung Dis. 2013;17:583-9.

7. World Health Organisation: Tobacco control-overview (2014), http:// www.afro.who.int/en/clusters-a-programmes/hpr/health-risk-factors/ tobacco/overview.html. Accessed 17 Oct 2014.

8. Pai M, Lee C-H, Lee M-C, Lin H-H, Shu C-C, Wang J-Y, et al. Pulmonary tuberculosis and delay in anti-tuberculous treatment are important risk factors for chronic obstructive pulmonary disease. PLoS One. 2012;7:e37978.

9. Arjomandi M, Faner R, Gonzalez N, Cruz T, Kalko SG, et al. Systemic inflammatory response to smoking in chronic obstructive pulmonary disease: evidence of a gender effect. PLoS One. 2014;9:e97491.

10. World Health Organisation: The 10 leading causes of death by country income group (2012) http://www.who.int/mediacentre/factsheets/fs310/ en/index1.html. Accessed 12 Dec 2014.

11. Lopez AD, Mathers CD, Ezzati M, Jamison DT, Murray CJ. Global and regional burden of disease and risk factors, 2001: systematic analysis of population health data. Lancet. 2006;367:1747-57.

12. Global initiative for chronic obstructive lung disease (GOLD): Global strategy for the diagnosis, management and prevention of COPD (2013), http://www.goldcopd.org. Accessed 10 Oct 2014.

13. Pellegrino R, Viegi G, Brusasco V, Crapo RO, Burgos F, Casaburi R, et al. Interpretative strategies for lung function tests. Eur Respir J. 2005;26:948-68.

14. Bureau Central des Recensements et des Etudes de Population: Rapport national sur l'etat de la population (2011), http://www.bucrep. Accessed 21 Sep 2014.

15. Organisation Mondiale de la Santé. Les jeunes et la santé: Défi pour la société (1986), http://whqlibdoc.who.int/trs/WHO_TRS_731_fre.pdf. Accessed 15 Jan 2015.

16. Buist AS, Vollmer WM, Sullivan SD, Weiss KB, Lee TA, Menezes AM, et al. The burden of obstructive lung disease initiative (bold): rationale and design. COPD. 2005;2:277-83.

17. Ferris BG. Epidemiology standardization project (American Thoracic Society). Am Rev Respir Dis. 1978;118:1-120.

18. Miller MR, Hankinson J, Brusasco V, Burgos F, Casaburi R, Coates A, et al. Standardisation of spirometry. Eur Respir J. 2005;26:319-38.

19. Brusasco VCRVG. Standardisation des explorations fonctionnelles respiratoires. Eur Respir J. 2005;2005(26):19-338.

20. Musafiri S, van Meerbeeck JP, Musango L, Derom E, Brusselle G, Joos G, et al. Spirometric reference values for an East-African population. Respiration. 2013;85:297-304.

21. Global Initiative for Chronic Obstructive Lung Disease (GOLD): Global strategy for the diagnosis, management, and prevention of COPD. Executive summary (2007), http//www.goldcopd.org/uploads/users/files/ GOLDReport07_0108.pdf. Updated 2007.

22. Musafiri S, van Meerbeeck J, Musango L, Brusselle G, Joos G, Seminega B, et al. Prevalence of atopy, asthma and COPD in an urban and a rural area of an African country. Respir Med. 2011;105:1596-605.

23. Gathuru IM, Bunker CH, Ukoli FA, Egbagbe EE. Differences in rates of obstructive lung disease between africans and african americans. Ethn Dis. 2002;12:S3-107-113.

24. Vollmer WM, Gislason T, Burney P, Enright PL, Gulsvik A, Kocabas A, et al. Comparison of spirometry criteria for the diagnosis of copd: results from the bold study. Eur Respir J. 2009;34:588-97.

25. Tilert T, Dillon C, Paulose-Ram R, Hnizdo E, Doney B. Estimating the U.S prevalence of chronic obstructive pulmonary disease using pre- and post-bronchodilator spirometry: the National Health And Nutrition Examination Survey (NHANES) 2007-2010. Respir Res. 2013;14:103. 
26. Ching SM, Pang YK, Price D, Cheong AT, Lee PY, Irmi I, Faezah H, Ruhaini I, Chia YC. Detection of airflow limitation using a handheld spirometer in a primary care setting. Respirology. 2014;19:689-93.

27. Cerveri I, Corsico AG, Accordini S, Niniano R, Ansaldo E, Anto JM, et al. Underestimation of airflow obstruction among young adults using FEV1/ FVC $<70 \%$ as a fixed cut-off: a longitudinal evaluation of clinical and functional outcomes. Thorax. 2008;63:1040-5.

28. Swanney MP, Ruppel G, Enright PL, Pedersen OF, Crapo RO, Miller MR, et al. Using the lower limit of normal for the FEV1/FVC ratio reduces the misclassification of airway obstruction. Thorax. 2008;63:1046-51.
29. Buist AS, Vollmer WM, McBurnie MA. Worldwide burden of COPD in highand low-income countries. Part 1. The burden of obstructive lung disease (BOLD) initiative. Int J Tuberc Lung Dis. 2008;12:703-8.

30. Adeloye D, Basquill C, Papana A, Chan KY, Rudan I, Campbell H. An estimate of the prevalence of COPD in Africa: a systematic analysis. COPD. 2015;12:71-81.

31. van Gemert F, Kirenga B, Chavannes N, Kamya M, Luzige S, Musinguzi P, et al. Prevalence of chronic obstructive pulmonary disease and associated risk factors in Uganda (FRESH AIR Uganda): a prospective crosssectional observational study. Lancet Glob Health. 2015;3:e44-51.

\section{Submit your next manuscript to BioMed Central and we will help you at every step:}

- We accept pre-submission inquiries

- Our selector tool helps you to find the most relevant journal

- We provide round the clock customer support

- Convenient online submission

- Thorough peer review

- Inclusion in PubMed and all major indexing services

- Maximum visibility for your research

Submit your manuscript at www.biomedcentral.com/submit
Biomed Central 